\title{
Protein adsorption on heterogeneous surfaces
}

\author{
Nitesh Aggarwal, ${ }^{1,2}$ Ken Lawson, ${ }^{1}$ Matthew Kershaw, ${ }^{1}$ Robert Horvath, ${ }^{1, a)}$ and \\ Jeremy Ramsden ${ }^{1, b)}$ \\ ${ }^{1}$ Department of Materials, Cranfield University, Bedfordshire MK43 OAL, United Kingdom \\ ${ }^{2}$ Department of Metallurgical Engineering and Materials Science, Indian Institute of Technology Bombay, \\ Powai, Mumbai 400076, India
}

(Received 5 November 2008; accepted 3 January 2009; published online 26 February 2009)

\begin{abstract}
The adsorption of the protein bovine serum albumin from an aqueous solution onto substrata made from pure silica, pure zirconia, and a mixture of the two has revealed that the adsorption behavior of the protein onto the mixture very significantly diverges from the corresponding mean of the behaviors with the pure substrata. A tentative explanation in terms of matching substratum heterogeneity with protein surface heterogeneity is offered. (C) 2009 American Institute of Physics. [DOI: $10.1063 / 1.3078397]$
\end{abstract}

Many attempts to predict the adsorption equilibria and kinetics of proteins at a solid/liquid interface assume the protein to be a uniform geometrical object, although this approach may be inadequate: Serum albumin, the most abundant blood protein, ${ }^{1}$ is predicted to be repelled so strongly from glass and silica using mean parameters for calculating the interfacial energy ${ }^{2}$ that it is doubtful whether it would ever absorb significantly, whereas countless experiments show that it is strongly adsorbed and rapidly forms a monolayer (e.g., Ref. 3); van Oss et al. ${ }^{4}$ conjectured that either the chemically heterogeneous and morphologically irregular surface of the protein itself is responsible for this discrepancy or substratum heterogeneity or both. In commercial silica glass, heterogeneity may be present due to foreign ions such as $\mathrm{Ca}^{2+}$ but this does not explain why serum albumin adsorbs strongly on pure silica.

The chemical heterogeneity of protein surfaces is well known; of particular relevance for protein adsorption under physiological conditions is the distribution of electron donor and electron acceptor residues. ${ }^{2,5}$ Quantitative scrutiny reveals that on the surface of serum albumin, their distribution is not random (statistically uniform) as it appears at first glance but has a scale-dependent excess of electron acceptor or donor potential; ${ }^{6}$ at the largest scale (i.e., that of the whole protein) there is an excess of the electron donor potential, which is why the protein is predicted to be repelled from the electron-donating surface of silica; at very small scales, there is an excess of electron acceptor potential, resulting in attraction. We ask whether a commensurate scale of electron donor and acceptor heterogeneity of an adsorbent substratum results in "anomalous" adsorption behavior of the protein.

Most protein adsorption experiments have been carried out on pure homogeneous surfaces or natural surfaces (including commercial glass) of undocumented heterogeneity at the nanoscale. The only reported examples of the deliberate use of synthetic heterogeneous surfaces used a mixture of silica and titania, ${ }^{7,8}$ but since both these materials are strong electron donors with rather similar surface interfacial properties $^{2,5}$ and, moreover, form a solid solution and hence lack heterogeneity at the scale of interest, these results are of

\footnotetext{
${ }^{a)}$ Present address: MTA-MFA (KFKI), Konkoly Thege Miklós út 29-33, H-1121 Budapest.

b) Electronic mail: j.ramsden@ cranfield.ac.uk.
}

little interest from our present viewpoint. A more interesting pair is silica and zirconia, the latter having a relatively strong electron acceptor potential, ${ }^{2,5}$ and the isoelectric points of both lie below $p \mathrm{H} 6 .{ }^{5,9}$ Furthermore, these two materials are not atomically miscible in all proportions.

We used high-resolution time-resolved optical waveguide lightmode spectroscopy (OWLS) ${ }^{10,11}$ to precisely measure the adsorption of serum albumin on pure silica, pure zirconia, and a mixture of the two. Monomode planar pyrolyzed sol-gel $\mathrm{Si}_{0.6} \mathrm{Ti}_{0.4} \mathrm{O}_{2}$ optical waveguides (MicroVacuum, Budapest) incorporated a shallow $(5-10 \mathrm{~nm})$ grating coupler (grating constant $416 \mathrm{~nm}$ ) (type 2400) and had surface roughness, measured by atomic force microscopy using standard tips of about $1 \mathrm{~nm}$. Pure silica (pyrolyzed sol-gel) and pure zirconia ( $e$-beam evaporation) coated waveguides were from MicroVacuum. For the silica-zirconia mixture, uncoated waveguides were cleaned ultrasonically in ultrapure water for $10 \mathrm{~min}$ at room temperature, followed by rinsing with ultrapure water, repeated using acetone instead of water, and isopropyl alcohol instead of acetone, placed in a vacuum chamber, evacuated to 0.01 Torr, filled with $10 \%$ oxygen and $90 \%$ argon, and etched for 2 min with a $20 \mathrm{~W}$ plasma. The magnetron sputtering vacuum chamber was evacuated to 2 $\times 10^{-6}$ Torr and backfilled with high purity argon $+10 \%$ oxygen to $8 \times 10^{-3}$ Torr ionized by applying radio frequency (200 W supplied by a $13.56 \mathrm{MHz}$ RFA power unit) to the cathode (target), a zirconia (containing $8 \% \mathrm{w} / \mathrm{w} \mathrm{Y}_{2} \mathrm{O}_{3}$ as stabilizer) $65 \mathrm{~mm}$ diameter disk on which small disks (their required area was estimated by separately measuring the deposition rates using pure targets under the same conditions $-40 \mathrm{~nm} / \mathrm{h}$ for both silica and zirconia) of pure silica were placed. The main vacuum chamber was the anode. Positive argon ions accelerated by a net negative voltage sputter-etched the source material, which then atomically nucleated onto the substrates approximately $7 \mathrm{~cm}$ distant from the cathode. These coatings replicate the initial surface finish of the substrates. Sputtering duration was $15 \mathrm{~min}$, giving a layer thickness of $10 \mathrm{~nm}$, which has been found sufficient to mask the underlying material. ${ }^{12}$ Environmental scanning electron microscopy (FEI XL30) revealed smooth, featureless surfaces after sputtering. Using X-ray photoelectron spectroscopy (VG Escalab II), the actual Si:Zr ratio was determined as 23.5:76.5 (mol \%). Assuming that the experimental equilibrium phase diagrams for bulk silica-zirconia 


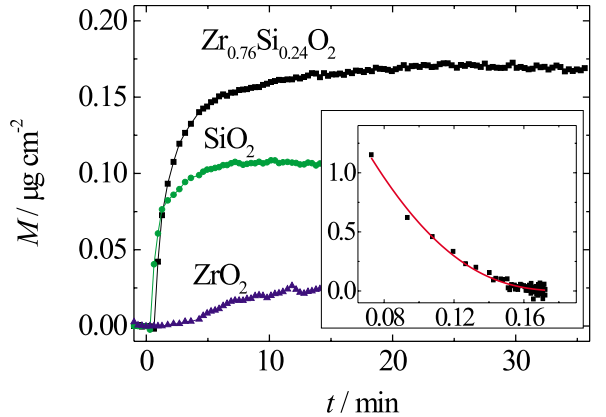

FIG. 1. (Color online) Plot of the adsorbed protein mass $M$ as a function of time $t$ for the three substrates: (from bottom to top) $\mathrm{ZrO}_{2}, \mathrm{SiO}_{2}$, and $\mathrm{Zr}_{0.76} \mathrm{Si}_{0.24} \mathrm{O}_{2}$. Inset: plot of the numerically differentiated $M(t)$ data (for adsorption to $\left.\mathrm{Zr}_{0.76} \mathrm{Si}_{0.24} \mathrm{O}_{2}\right)$ as a function of $M$. Abscissa: $M\left(\mu \mathrm{g} \mathrm{cm}^{-2}\right)$, ordinate: $d M / d t\left(\mathrm{ng} \mathrm{cm}^{-2} \mathrm{~s}^{-1}\right)$. The solid line shows the fitted RSA curve.

mixtures ${ }^{13}$ are valid for our thin films, its structure is a mixture of zirconium silicate, $\mathrm{ZrSiO}_{4}(65 \%)$, and a solid solution of zirconia and silica (35\%).

Waveguides were equilibrated overnight in aqueous $p \mathrm{H} \quad$ buffer $\quad\left[0.01 M \quad N\right.$-2-hydroxyethylpiperazine- $N^{\prime}-2$ ethanesulfonic acid- $\mathrm{NaOH}, p \mathrm{H}$ 7.4] and mounted as the floor of a microfluidic chamber in an OWLS-110 (MicroVacuum) integrated optical scanner with which the effective refractive indices of the zeroth transverse magnetic and electric modes were measured. Solutions were impelled through the chamber (wall shear rate $31 \mathrm{~s}^{-1}$ ) using a peristaltic pump. As soon as the baseline was established (i.e., after a few minutes), bovine serum albumin (BSA) (Sigma, $\geq 98 \%$ pure) solution made up at a bulk concentration $c_{b}$ of $100 \mu \mathrm{g} / \mathrm{cm}^{3}$ in the buffer was admitted at the same flow rate. Flow continued until the response saturated. Upon dilution with pure buffer, there was no significant desorption. Experiments were carried out at a temperature of $25.0 \pm 0.2{ }^{\circ} \mathrm{C}$.

The mode equations ${ }^{14}$ were solved to yield the thickness $d_{A}$ and refractive index $n_{A}$ of the adsorbed protein layer. ${ }^{15}$ Birefringence was evaluated ${ }^{16}$ and found to be negligible for BSA on pure silica and mixed silica-zirconia but negative for BSA on pure zirconia (this does not affect the evaluation of the adsorbed mass). $d_{A}$ and $n_{A}$ were combined to yield the mass $M$ of adsorbed albumin molecules according to ${ }^{17} M=d_{A}\left(n_{A}-n_{C}\right) /(d n / d c)$, using $d n / d c$ (albumin) $=0.182 \mathrm{~cm}^{3} / \mathrm{g}$.

Figure 1 shows the time course of protein adsorption. The $M(t)$ data were numerically differentiated and plotted against $M$ (inset of Fig. 1) and modeled as random sequential addition (RSA), ${ }^{18}$

$$
d M / d t=k_{a} c_{b} \phi(M, a),
$$

where $k_{a}$ is the adsorption rate coefficient and $\phi(M, a)$ is the available area function (i.e., the fraction of the surface available for accepting a protein for adsorption). Equation (1) was fitted to the plots with $k_{a}$ and the area $a$ occupied by one protein as free parameters, using $\phi$ and a jamming limit $\theta_{J}$ of 0.54 (appropriate for spheres and a range of spherocylinders).${ }^{19}$ The results are given in Table I.

Clearly, adsorption on the three substrata is very different. Even simple visual inspection shows that the behavior on the mixed film is far from the weighted arithmetic mean of the adsorption to its pure components separately, which is what simple protein adsorption theory predicts. ${ }^{20}$
TABLE I. Adsorption parameters for $0.1 \mathrm{mg} / \mathrm{cm}^{3}$ BSA on different substrates at $25{ }^{\circ} \mathrm{C} . M_{J}^{\text {(meas) }}$ is the highest observed adsorbed amount (in $\left.\mu \mathrm{g} \mathrm{cm} \mathrm{s}^{-1}\right) \cdot a^{(J)}$ is calculated from $M_{J}^{(\text {meas) }}$ using Eq. (2) and $\theta_{J}=0.54$ (Refs. 18 and 19). The estimated uncertainties are $\pm 10 \%$.

\begin{tabular}{lcccc}
\hline \hline Substrate & $M_{J}^{(\text {meas })}$ & $\begin{array}{c}a^{(J)} \\
\left(\mathrm{nm}^{2}\right)\end{array}$ & $\begin{array}{c}a \\
\left(\mathrm{~nm}^{2}\right)\end{array}$ & $\begin{array}{c}k_{a} \\
\left(\mathrm{~cm} \mathrm{~s}^{-1}\right)\end{array}$ \\
\hline $\mathrm{SiO}_{2}$ & 0.11 & 54 & 44 & $2.0 \times 10^{-5}$ \\
$\mathrm{ZrO}_{2}$ & 0.03 & 198 & 122 & $6.4 \times 10^{-7}$ \\
$\mathrm{Zr}_{0.76} \mathrm{Si}_{0.24} \mathrm{O}_{2}$ & 0.17 & 35 & 31 & $3.4 \times 10^{-5}$ \\
\hline \hline
\end{tabular}

On all three substrata, adsorption saturates at what is presumably a monolayer. Since, however, the adsorbed amounts are very different, the structures of the proteins in the monolayers must be correspondingly different. On pure silica and on silica-zirconia adsorption is clearly RSA, as inferred from the excellent fits to the theoretical prediction [Eq. (1)]. The data for the adsorption on zirconia are too noisy to be able to be as confident regarding the mode of adsorption as in the other two cases.

Let us compare the values of $a$ obtained via fitting the RSA model [Eq. (1)] to those predicted from the adsorption plateau $M_{J}$ according to ${ }^{10}$

$$
a^{(J)}=\theta_{J} m / M_{J},
$$

(results in Table I) where $m$ is the mass of one albumin molecule $(0.11 \mathrm{ag})$. $a$ from the RSA fit is dominated by adsorption on a relatively empty surface, and that deduced from Eq. (2) is dominated by the final size of the adsorbed protein. For the mixed film, $a^{(J)} \approx a$ (within experimental uncertainty) and corresponds to that predicted from the structure of the molecule. ${ }^{21}$ For pure silica $a^{(J)}>a$ (the discrepancy exceeds experimental uncertainty), and for pure zirconia $a^{(J)} \gg a$.

The origin of the differences between the three substrata may lie in increasingly rapid (compared to the characteristic adsorption time $\tau_{a} \approx a^{1 / 2} / k_{a}$ ) denaturation of the adsorbed protein. It is well known, and theoretically understood, ${ }^{22}$ that proteins tend to denature when adsorbed on substrata: they may exchange their own intramolecular bonds for ones between the polypeptide chain and the adsorbing substrate, and even if there is no enthalpy change in the process, the gain of entropy provides sufficient free energy for the denaturation. Since globular proteins such as serum albumin have a hydrophobic core, ${ }^{23}$ there will be a significant enthalpic advantage if they are everted on hydrophobic zirconia, enabling the hydrophobic core to bond with it, ${ }^{24}$ adding to the entropic gain. ${ }^{22}$ Our inferred molecular area data imply that the protein adsorbs in its native (solution) form onto $\mathrm{Zr}_{0.76} \mathrm{Si}_{0.24} \mathrm{O}_{2}$, in a somewhat denatured form onto $\mathrm{SiO}_{2}$, and in a maximally denatured form onto $\mathrm{ZrO}_{2}$.

TABLE II. Single-substance surface tensions of water, albumin, and the pure substrata (Refs. 2 and 5).

\begin{tabular}{lccc}
\hline \hline Substance & $\begin{array}{c}\gamma^{(\mathrm{LW})} \\
\left(\mathrm{mJ} \mathrm{m}^{-2}\right)\end{array}$ & $\begin{array}{c}\gamma^{\oplus} \\
\left(\mathrm{mJ} \mathrm{m}^{-2}\right)\end{array}$ & $\begin{array}{c}\gamma^{\ominus} \\
\left(\mathrm{mJ} \mathrm{m}^{-2}\right)\end{array}$ \\
\hline Serum albumin & 27 & 6.3 & 51 \\
$\mathrm{SiO}_{2}$ & 39 & 0.8 & 41 \\
$\mathrm{ZrO}_{2}$ & 35 & 1.3 & 3.6 \\
$\mathrm{H}_{2} \mathrm{O}$ & 22 & 25.5 & 25.5 \\
\hline \hline
\end{tabular}


TABLE III. (A) Interfacial interaction energies calculated (Refs. 2 and 5) from the data given in Table II, assuming that the $\mathrm{Zr}_{0.76} \mathrm{Si}_{0.24} \mathrm{O}_{2}$ is a solid solution of its pure components. (B) Protein adsorbed layer thickness and refractive index and quantities derived therefrom: protein density $\rho=\left(n_{A}\right.$ $\left.-n_{C}\right) /(d n / d c)$ and protein concentration in the layer $c_{A}=M_{J}^{(\text {meas })} / d_{A}$.

\begin{tabular}{lccccc}
\hline \hline Substratum & $\begin{array}{c}\Delta G_{123}^{\|} \\
\left(\mathrm{mJ} \mathrm{m}^{-2}\right)\end{array}$ & $\begin{array}{c}d_{A} \\
(\mathrm{~nm})\end{array}$ & \multicolumn{1}{c}{$n_{A}$} & $\begin{array}{c}\rho \\
\left(\mathrm{g} \mathrm{cm}^{-3}\right)\end{array}$ & $\begin{array}{c}c_{A} \\
\left(\mathrm{~g} \mathrm{~cm}^{-3}\right)\end{array}$ \\
\hline $\mathrm{SiO}_{2}$ & 22.7 & 2.7 & 1.41 & 0.43 & 0.41 \\
$\mathrm{ZrO}_{2}$ & -0.9 & 0.1 & 1.8 & 2.6 & 3.0 \\
$\mathrm{Zr}_{0.76} \mathrm{Si}_{0.24} \mathrm{O}_{2}$ & 7.6 & 1.8 & 1.50 & 0.93 & 0.94 \\
\hline \hline
\end{tabular}

The adsorption rate coefficient $k_{a} \sim \exp \left[-\Delta G_{a} /\left(k_{B} T\right)\right],{ }^{20}$ where the adsorption energy barrier $\Delta G_{a} \approx a \Delta G_{123}^{\|} ; \Delta G_{123}^{\|}$, the interfacial interaction energy per unit area between parallel planar surfaces of albumin (subscript 3 ) and the substratum (subscript 1) in the presence of water (subscript 2), can be computed from Dupré-like laws and literature values of the corresponding single-substance surface tensions (Table II) ${ }^{2,5}$ with the results given in Table III. Not only do these estimates predict a far greater difference between $k_{a}$ for silica and for the mixture than is actually observed, but adsorption on zirconia should be transported-limited, whereas according to our measurements it is 50 times slower than on silica.

According to the simple concept of protein adsorption, the conformational change (eversion) takes place after the protein is on the surface. Yet adsorption both on the mixture and on pure silica can be well fitted to an RSA model, and even if a postadsorption transition needs to be explicitly considered (cf. Ref. 25), we still need to understand why the primary arrival at the zirconia surface is so slow. Given that on both pure silica and zirconia $a$ exceeds the value expected from the native form of the protein, we infer that conformational change already starts to take place before the protein actually arrives at the surface; it is expected that the water structure is different in the vicinity of these very different surfaces, ${ }^{26}$ which has strong implications for protein stability. ${ }^{27}$

Figure 2 plots the adsorbed protein monolayer thickness and isotropic refractive index; their plateau values are given in Table III. One may infer the protein density (concentration) in the adsorbed layer from either the thickness or the refractive index; the values (Table III) are in reasonable agreement with one another. Comparison with the reciprocal partial specific volume $\rho_{m}$ of the serum albumin molecule ${ }^{28}$ $\left(1.4 \mathrm{~g} / \mathrm{cm}^{3}\right)$ is revealing. ${ }^{28}$ The value of $\rho$ for albumin on

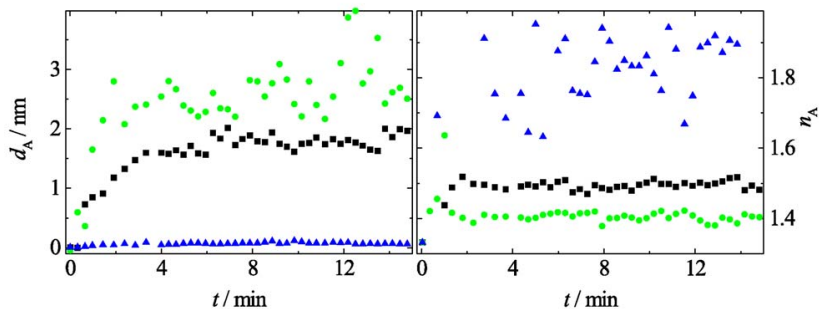

FIG. 2. (Color online) Plot of the evolution of the thickness $d_{A}$ (left) and refractive index $n_{A}$ (right) of the adsorbed protein layer for the three substrata: $\mathrm{ZrO}_{2}$ [(blue) triangles], $\mathrm{Zr}_{0.76} \mathrm{Si}_{0.24} \mathrm{O}_{2}$ [(black) squares], and $\mathrm{SiO}_{2}$ [(green) circles]. zirconium silicate is a reasonable approximation to $\rho_{m} \theta_{J}$; for the protein on zirconia it indicates a dense, compactified denatured layer. The value on silica is, in contrast, very low, suggesting a curious open kind of structure.

On the basis of preservation of native protein structure, we conclude that zirconium silicate has better biocompatibility than pure silica and pure zirconia. It remains to be seen whether this is due to nanoscale heterogeneity of the substratum (small patches of the zirconium silicate complementary to the protein surface heterogeneity) or an unusual decay profile of the electron donor/acceptor interaction between zirconium silicate and albumin. Note that we have assumed that the surface roughnesses of all three substrata are the same. An implication for the design of biomedical surfaces designed to come into contact with the blood is that mixed oxides should be added to the repertoire of the presently mainly pure finishes to biomedical devices.

We thank John R. Nicholls for an illuminating discussion on the possible structure of the silica-zirconia. J.R. thanks A. D. R (Tony) Haymet for a previous discussion on electron donor/acceptor decay profiles. N.A. thanks the Collegium Basilea (Institute of Advanced Study) for a scholarship.

${ }^{1}$ Human Protein Data, edited by A. Heberle (VCH, New York, 1983), Vols. 1 and 2.

${ }^{2}$ C. J. van Oss, Forces Interfaciales en Milieux Aqueux (Masson, Paris, 1996).

${ }^{3}$ H. B. Bull, Biochim. Biophys. Acta 19, 464 (1956).

${ }^{4}$ C. J. van Oss, W. Wu, and R. F. Giese, ACS Symp. Ser. 602, 80 (1995).

${ }^{5}$ M. G. Cacace, E. M. Landau, and J. J. Ramsden, Q. Rev. Biophys. 30, 241 (1997)

${ }^{6}$ C. Calonder, J. Talbot, and J. J. Ramsden, J. Phys. Chem. B 105, 725 (2001).

${ }^{7}$ R. Kurrat, J. J. Ramsden, and J. E. Prenosil, J. Chem. Soc., Faraday Trans. 90, 587 (1994).

${ }^{8}$ R. Kurrat, J. E. Prenosil, and J. J. Ramsden, J. Colloid Interface Sci. 185 , 1 (1997).

${ }^{9}$ N. Whitehead, M.S. thesis, Loughborough University, 1997.

${ }^{10}$ J. J. Ramsden, J. Stat. Phys. 73, 853 (1993).

${ }^{11}$ J. J. Ramsden, Colloids Surf., A 141, 287 (1998).

${ }^{12}$ R. Kurrat, M. Textor, J. J. Ramsden, P. Böni, and N. D. Spencer, Rev. Sci. Instrum. 68, 2172 (1997).

${ }^{13}$ E. M. Levin, C. R. Robbins, and H. F. McMurdie, Phase Diagrams for Ceramicists (American Ceramic Society, Columbus, Ohio, 1964).

${ }^{14}$ K. Tiefenthaler and W. Lukosz, J. Opt. Soc. Am. B 6, 209 (1989).

${ }^{15}$ L. Guemouri, J. Ogier, Z. Zekhnini, and J. J. Ramsden, J. Chem. Phys. 113, 8183 (2000)

${ }^{16}$ R. Horvath and J. J. Ramsden, Langmuir 23, 9330 (2007).

${ }^{17}$ V. Ball and J. J. Ramsden, Biopolymers 46, 489 (1998).

${ }^{18}$ P. Schaaf and J. Talbot, J. Chem. Phys. 91, 4401 (1989).

${ }^{19}$ P. Viot, G. Tarjus, S. M. Ricci, and J. Talbot, J. Chem. Phys. 97, 5212 (1992).

${ }^{20}$ J. J. Ramsden, in Encyclopaedia of Surface and Colloid Science, edited by A. Hubbard (Dekker, New York, 2002), pp. 240-261.

${ }^{21}$ D. C. Carter and J. X. Ho, Adv. Protein Chem. 45, 153 (1994).

${ }^{22}$ A. Fernández and J. J. Ramsden, J. Biol. Phys. Chem. 1, 81 (2001).

${ }^{23}$ M. Pirtskhalava, B. Vishnepolsky, and G. Managadze, J. Biol. Phys. Chem. 2, 1 (2002).

${ }^{24}$ S. N. Timasheff and T. Arakawa, J. Cryst. Growth 90, 39 (1988).

${ }^{25}$ P. R. Van Tassel, L. Guemouri, J. J. Ramsden, G. Tarjus, P. Viot, and J. Talbot, J. Colloid Interface Sci. 207, 317 (1998).

${ }^{26}$ P. M. Wiggins, J. Biol. Phys. Chem. 2, 25 (2002).

${ }^{27}$ A. Dér, L. Kelemen, L. Fábián, S. G. Taneva, E. Fodor, T. Páli, A. Cupane, M. G. Cacace, and J. J. Ramsden, J. Phys. Chem. B 111, 5344 (2007)

${ }^{28}$ P. A. Charlwood, J. Am. Chem. Soc. 79, 776 (1957). 
2009

\section{Protein adsorption on heterogeneous surfaces}

\section{Aggarwal, Nitesh}

American Institute of Physics

Aggarwal, N., Lawson, K., Kershaw, M., Horvath, R. and Ramsden, J. 2009. Protein adsorption on heterogeneous surfaces. Applied physics letters, 94(8), paper 083110. DOI: 10.1063/1.3078397 https://dspace.lib.cranfield.ac.uk/handle/1826/9686

Downloaded from Cranfield Library Services E-Repository 